\title{
THE
}

\section{Effects of User Perceptions of SAP ERP System on User Learning and Skills}

Sung J. Shim

Minsuk K. Shim

University of Rhode Island, mshim@uri.edu

Follow this and additional works at: https://digitalcommons.uri.edu/education_facpubs

The University of Rhode Island Faculty have made this article openly available.

Please let us know how Open Access to this research benefits you.

This is a pre-publication author manuscript of the final, published article.

Terms of Use

This article is made available under the terms and conditions applicable towards Open Access

Policy Articles, as set forth in our Terms of Use.

\section{Citation/Publisher Attribution}

Shim, S.J., Shim, M.K. Effects of user perceptions of SAP ERP system on user learning and skills. J Comput High Educ 32, 41-56 (2020). https://doi.org/10.1007/s12528-019-09218-x

Available at: https://doi.org/10.1007/s12528-019-09218-x 


\title{
Effects of User Perceptions of SAP ERP System on User Learning and Skills
}

\author{
Sung J. Shim, Minsuk K. Shim
}

\begin{abstract}
This study examines the effects of playfulness and anxiety as perceived by users in relation to SAP enterprise resource planning (ERP) system on users' learning of business processes and users' skills to use the system. Data was collected from a survey of college students who took a course on business process integration with ERP system where students used SAP ERP system to complete course works on business processes. System playfulness is found to have a small positive effect on user learning and skills without any control but the positive effect disappears after controlling for gender and prior experiences. System anxiety is found to have a large negative effect on both user learning and skills. These results suggest that enhancing the playfulness of SAP ERP system can help improve the user's learning of business processes and the user's skills to use the system, but that reducing the anxiety of the system is far more important in improving the user's learning of business processes and the user's skills to use the system.
\end{abstract}

\section{Keywords}

Enterprise resource planning (ERP) - SAP - System playfulness - System anxiety - Business processes - User learning - User skills

\section{Introduction}

Enterprise resource planning (ERP) systems are "software systems that automate and integrate many or most of a firm's business processes" (Gattiker and Goodhue 2005, p. 560). SAP ERP system leads the ERP market with more than 12 million users, 121,000 installations worldwide, more than 1,500 SAP partners, over 25 industry-specific business solutions, and more than 41,200 customers in 120 countries (Lauchlan 2017). Further, more than 3,500 academic institutions in over 113 countries participate in the SAP University Alliances program (SAP University Alliances 2018), which enables the institutions to incorporate SAP ERP system into their curricula by partnering to provide students with a better understanding of business processes and build skills of SAP ERP system. While many students have come to learn about business processes and SAP ERP system, it seems that little is known about how much students learn about business processes by using SAP ERP system and gain skills to use the system. Further, it seems that few studies have examined the effects of users' perceptions towards SAP ERP system on their learning of business processes and skills to use the system.

The purpose of this study is twofold. First, the study attempts to examine the extent to which students have learned about business processes and the extent to which they have gained skills to use SAP ERP system after they took a semester-long course on business process integration with ERP system where they used SAP ERP system to complete course works on business processes. Second, the study attempts to examine the effects of playfulness of SAP ERP system as a positive factor and the effects of anxiety of SAP ERP system as a negative factor on learning of business processes and skills to use the system. On a theoretical level, this study can help advance our understanding of the effects of positive (i.e., system playfulness) and negative (i.e., system anxiety) perceptions on user learning and skills in the line of studies on computer self-efficacy. On a practical level, knowledge of users' perceptions towards SAP ERP system and associations of their perceptions with their learning of business processes and their skills to use the system could help predict user behavior regarding the system adoption and further help train users more effectively by enhancing user experiences with the system.

\section{Conceptual framework}

\section{Business processes and SAP ERP system}

ERP systems help organizations manage their business processes. An organization may perform various business processes to achieve its goals. Three key business processes of a typical manufacturing company are procurement, production, and fulfillment (Magal \& Word 2017). The procurement process involves the activities for purchasing or procuring the materials that the organization needs. The production process refers to the actual creation of products in the organization. The fulfillment process involves the activities for selling and delivering products to customers. In 
addition, the warehouse management process is concerned with the storage and movement of materials and products in the organization. While organizations may use other business processes, these four business processes are more directly related to creating and delivering products. Fig. 1 shows these four business processes and their interrelations in a typical manufacturing company.

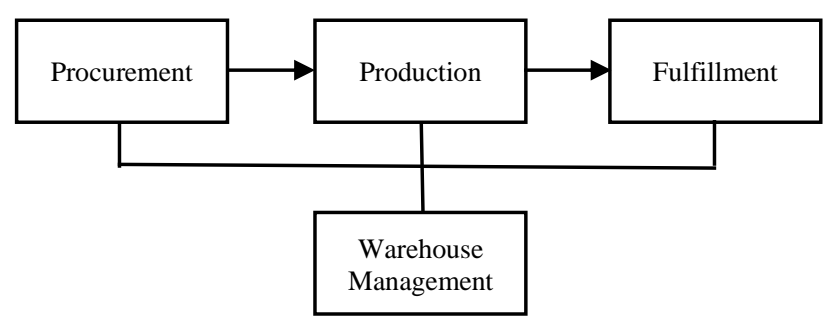

Fig. 1 Business processes

Positive and negative perceptions of system

Computer self-efficacy is defined as an individual's ability to use the computer to perform a specific task (Compeau \& Higgins 1995; Marakas et al. 1998; Mouakket 2010). Studies on computer self-efficacy suggest that computer selfefficacy is a significant determinant of an individual's intention to use computers (Venkatesh \& Davis 2000; Hung \& Liang 2001; Mouakket 2010). A wide body of research has investigated computer self-efficacy as it relates to ERP systems. For example, Elkhani et al. (2014) found that computer self-efficacy had a positive influence on usefulness and ease of use of ERP systems, which in turn had a positive influence on the user's usage of ERP systems. Mouakket (2010) also reported that computer self-efficacy had a significant impact on ease of use of ERP systems, which in turn had a positive impact on the user's utilization of ERP systems. Park et al. (2007) confirmed the positive effect of the ERP system on the absorptive capacity of users, including understanding, assimilating, and application of the ERP system on their ERP system usage.

This study attempts to extend this line of studies on computer self-efficacy of ERP systems by considering both system playfulness as a positive factor and system anxiety as a negative factor in the context of SAP ERP system. Also, previous studies in information systems adoption and implementation have examined the constructs of system playfulness and system anxiety to understand user perceptions towards to various information systems (Hackbarth et al. 2003). However, it seems that few have studied the constructs of system playfulness and system anxiety as they relate to SAP ERP system.

System playfulness refers to an individual's tendency to interact spontaneously with a computer (Webster 1989). Users tend to feel intimidated and stressed when they first interact with an information system, and so, playfulness with the system is low (Hackbarth et al 2003; Wildstrom 1998). Also, a strong, positive correlation between system experience and system playfulness was found (Webster \& Martocchio 1992) and system playfulness was found to be a positive mediator of the effect that system experience had on ease of use (Hackbarth et al. 2003). Terzis et al. (2018) found that playfulness was a direct determinant of continuance acceptance of computer-based assessment (CBA). Jo et al. (2016) reported that playfulness inspired great interest in students and greatly affected students' satisfaction of integrated teaching and learning assistance (ITLA) system. Hsu et al. (2012) reported that website quality affected customers' perceived playfulness, which in turn would influence their satisfaction and purchase intention. In the ERP system context, users were likely to perceive the system to be easier to use and so more likely to intend to use the system as they perceived the system to be more enjoyable (Herzig et al. 2012).

We hypothesize that users are likely to gain more knowledge of business processes as they perceive SAP ERP system to be more playful, and that users are likely to be more capable of performing tasks in SAP ERP system as they perceive SAP ERP system to be more playful.

H1: System playfulness is positively related to the learning of business processes.

H2: System playfulness is positively related to the skills to use SAP ERP system.

System anxiety is defined as the apprehension or fear that results when an individual is faced with the possibility of using a system (Simonson et al. 1987). When users initially interact with systems, they tend to feel anxious (Hackbarth et al. 2003; Ganzel 1998). Also, system anxiety was found to be a significant and negative mediator of the effect that system experience has on ease of use (Hackbarth et al. 2003). Jashapara \& Tai (2011) 
reported that computer anxiety mediated the effects of personal innovativeness with IT on ease of use in the e-learning system context. Laosethakul \& Leingpibul (2010) reported that computer anxiety had a direct influence on perception toward computing in a study of American and Chinese students. Saadé \& Kira (2009) showed that as student anxiety increased, the perception of ease of use of the learning management system (LMS) decreased.

We hypothesize that users are likely to gain more knowledge of business processes as they feel less anxious when using SAP ERP system, and that users are likely to be more capable of performing tasks in SAP ERP system as they feel less anxious when using SAP ERP system.

H3: System anxiety is negatively related to the learning of business processes.

H4: System anxiety is negatively related to the skills to use SAP ERP system.

This study attempts to extend the line of studies on system playfulness and system anxiety by considering the effects of both constructs on the user's learning of underlying domain knowledge of business processes and the user's skills to use the system in the context of SAP ERP system. Fig. 2 summarizes the research hypotheses discussed above.

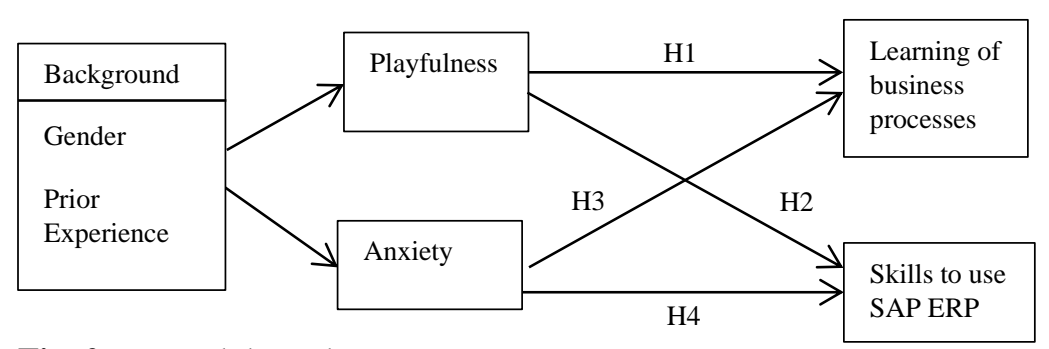

Fig. 2 Research hypotheses

\section{Methodology}

Data

Data was collected over two semesters from a survey of 140 upper-level undergraduate business students who took a course on business process integration with SAP ERP system, in which students used course materials provided by the SAP University Alliances Program. All the students took an introductory information technology management course as the prerequisite. Table 1 shows the survey participants' gender distribution and prior experiences with SAP ERP system and/or other ERP systems.

Table 1 Demographic characteristics

\begin{tabular}{llr}
\hline Gender & Number & $\%$ \\
\hline Male & 87 & 62.1 \\
Female & 42 & 30.0 \\
missing & 11 & 7.9 \\
Prior Experience & & \\
No experience with SAP and other ERP system & 84 & 60.0 \\
Experience with either SAP or another ERP system & 44 & 31.4 \\
Experience with both SAP and other ERP systems & 12 & 8.6 \\
\hline
\end{tabular}

\section{Measurement}

Aligned to the four business processes described above, the following five areas of domain knowledge are used in measuring the learning of business processes in this study: (1) knowledge of the procurement process and activities, (2) knowledge of the production process and activities, (3) knowledge of the fulfillment process and activities, (4) knowledge of the warehouse management process and activities, and (5) knowledge of interrelations and interdependencies between business processes.

The following seven areas of user ability are used in this study in measuring the skills to use SAP ERP system to perform transactions and understand the associated master data: (1) ability to carry out transactions for the procurement process in SAP ERP system, (2) ability to carry out transactions for the production process in SAP ERP system, (3) ability to carry out transactions for the fulfillment process in SAP ERP system, (4) ability to carry out 
transactions for the warehouse management process in SAP ERP system, (5) ability to create material master data in SAP ERP system, (6) ability to create customer master data in SAP ERP system, and (7) ability to create vendor master data in SAP ERP system. The first four areas of user abilities to use SAP ERP system are aligned with the four main business processes in Fig. 1, respectively. The last three areas of user abilities to use SAP ERP system are about the master data needed to perform the four main business processes (Magal \& Word 2017).

In this study, we used the items for the constructs of system playfulness and system anxiety adopted from Hackbarth et al. (2003). Two demographic variables were included to control for student intake characteristics: gender and prior experiences with SAP ERP system and/or other ERP systems. Based upon students' responses on their prior learning or use of the system, we classified them into 3 groups: no prior experience with SAP and other ERP systems, some prior experience with either SAP system or other ERP systems, and some prior experience with both SAP system and other ERP systems. As these demographic variables are categorical, we used three dummy coded variables in the analyses: one for gender (Female), two for prior experience (SomeExp, BothExp) (see Table 1). Table 2 shows the inter-correlations among the four constructs of interests. All the correlations were significant.

Table 2 Inter-correlations among four constructs

\begin{tabular}{lcccc}
\hline Variables & Playfulness & Anxiety & Knowledge & Skill \\
\hline Playfulness & & $-0.246^{* *}$ & $0.180^{*}$ & $0.180^{*}$ \\
Anxiety & $-0.246^{* *}$ & & $-0.564^{* * *}$ & $-0.593^{* * *}$ \\
Knowledge & $0.180^{*}$ & $-0.564^{* * *}$ & & $0.789^{* * *}$ \\
Skill & $0.180^{*}$ & $-0.593^{* * *}$ & $0.789^{* * *}$ & \\
\hline
\end{tabular}

$* \mathrm{p}<0.05, * * \mathrm{p}<0.01, * * * \mathrm{p}<0.001$

Tables 3, 4, 5, and 6 show the composite variables and their items of (1) learning of business processes, (2) skills to use SAP ERP system, (3) system playfulness, and (4) system anxiety, respectively. The extent of agreement on each study item was measured using a 7-point Likert-type scale ranging from 'strongly disagree' $(=1)$ to 'strongly agree' $(=7)$. Students filled in the survey in the last week of the semester after they practiced with SAP ERP system for all four business processes.

\section{Data analysis}

Data collected was analyzed in three steps. First, the descriptive statistics were used to explore students' perceptions of their knowledge and skill development. Second, the factor analyses were performed to see the appropriateness of the psychometric properties of the following measures: system playfulness, system anxiety, knowledge and skills items. Third, the effects of system playfulness and system anxiety on learning of business processes and skills to use SAP ERP system were explored through regression analyses.

\section{Results}

\section{Assessment of user Learning and skills}

Table 3 shows the mean values and the percent of students at different levels for the five areas of knowledge of business processes. It is worth noting that the mean values do not vary much across the five areas of knowledge, ranging from 4.73 to 4.79 . These results indicate that the respondents perceived as they had a high level of general knowledge on all four key business processes and their inter-relatedness. More than half of the respondents rated their knowledge at the high level whereas approximately $18 \%$ of the respondents rated their knowledge of business processes at the low level.

Table 3 Results of learning of business processes

\begin{tabular}{|c|c|c|c|c|c|}
\hline \multirow[t]{2}{*}{ Knowledge of business processes } & \multirow[b]{2}{*}{ Mean } & \multirow[b]{2}{*}{ St. Dev. } & \multicolumn{3}{|c|}{$\%$ of students } \\
\hline & & & Low $^{1}$ & Middlle $^{2}$ & $\mathrm{High}^{3}$ \\
\hline Knowledge of the procurement process and activities & 4.74 & 1.357 & 17.5 & 27.0 & 55.5 \\
\hline Knowledge of the production process and activities & 4.77 & 1.324 & 16.1 & 27.7 & 56.2 \\
\hline Knowledge of fulfillment process and activities & 4.79 & 1.396 & 17.5 & 24.8 & 57.7 \\
\hline Knowledge of the warehouse management process and activities & 4.75 & 1.316 & 17.5 & 26.3 & 56.2 \\
\hline Knowledge of interrelations and interdependencies between business processes & 4.73 & 1.347 & 18.4 & 26.5 & 55.1 \\
\hline
\end{tabular}

"Combination of "Very low," "Low," and "Somewhat low"

2 "Neither low nor high"

${ }^{3}$ Combination of "Somewhat high," "High," and "Very high" 
Table 4 shows the mean values and the percent of respondents at different levels for the seven areas of skills to use SAP ERP system. The mean values do not vary much across the seven areas of skills, ranging from 4.85 to 5.01 . These results indicate that the respondents have high levels of skills to use SAP ERP system to perform transactions and understand the associated master data. The respondents rated slightly higher for their skills in using the system (mean $=4.92)$ than their knowledge of business processes (mean $=4.76)$. Fifty-eight to sixty-five percent of respondents rated their skills at the high level whereas $14 \%$ to $17 \%$ of the respondents rated their skills to use SAP ERP system at the low level. The respondents appear to feel least confident about their skills in carrying out transactions for warehouse management process in SAP ERP system than other areas.

Table 4 Results of skills to use SAP ERP system

\begin{tabular}{|c|c|c|c|c|c|}
\hline \multirow{2}{*}{$\begin{array}{l}\text { Skills to use SAP ERP system: } \\
\text { Ability to }\end{array}$} & \multirow[b]{2}{*}{ Mean } & \multirow[b]{2}{*}{ St. Dev. } & \multicolumn{3}{|c|}{$\%$ of students } \\
\hline & & & Low $^{1}$ & Middlle $^{2}$ & $\mathrm{High}^{3}$ \\
\hline Carry out transactions for the procurement process & 4.88 & 1.321 & 15.9 & 21.7 & 62.3 \\
\hline Carry out transactions for the production process & 4.90 & 1.309 & 13.8 & 23.2 & 63.0 \\
\hline Carry out transactions for the warehouse management process & 4.85 & 1.277 & 13.9 & 27.7 & 58.4 \\
\hline Create material master data & 4.93 & 1.297 & 14.5 & 24.6 & 60.9 \\
\hline Create customer master data & 5.01 & 1.370 & 15.2 & 20.3 & 64.5 \\
\hline Create vendor master data & 4.99 & 1.367 & 13.8 & 22.5 & 63.8 \\
\hline
\end{tabular}

${ }^{1}$ Combination of "Very low," "Low," and "Somewhat low"

2 "Neither low nor high"

${ }^{3}$ Combination of "Somewhat high," "High," and "Very high"

Table 5 shows the mean values and the percent of the respondents at different levels of agreement for system playfulness items. Three items were worded in negative terms and those items were recoded so that all items were in the same direction. The mean values do not vary much across the seven items, ranging from 3.83 to 4.25 with larger standard deviations than other measures. These results indicate that the respondents' perceptions towards SAP ERP are somewhat neutral as being neither playful nor unplayful. The respondents disagreed most about their interaction with SAP system being "imaginative" (mean = 3.83). Thirty-one to forty-nine percent of the respondents agreed with their interaction with SAP system being playful whereas $26 \%$ to $41 \%$ of the respondents disagreed. The respondents agreed more on the items such as "flexible," "spontaneous," and "creative." Students agreed less on the items such as "imaginative," "original," "playful," and "inventive."

Table 5 Results of system playfulness

\begin{tabular}{llllll}
\hline System playfulness & & & \multicolumn{3}{c}{ \% of students } \\
\cline { 4 - 6 } & Mean & St. Dev. & Disgaree $^{2}$ & Neutral $^{3}$ & Agree $^{4}$ \\
\hline Spontaneous & 4.25 & 1.693 & 26.4 & 27.1 & 46.4 \\
Imaginative $^{1}$ & 3.83 & 1.531 & 41.4 & 27.1 & 31.4 \\
Flexible & 4.33 & 1.642 & 31.4 & 19.3 & 49.3 \\
Creative & 4.21 & 1.686 & 32.9 & 22.1 & 45.0 \\
Playful & 4.00 & 1.831 & 36.4 & 24.3 & 39.3 \\
Original $^{1}$ & 4.06 & 1.577 & 31.4 & 34.3 & 34.3 \\
Inventive $^{1}$ & 4.14 & 1.594 & 32.9 & 29.3 & 37.9 \\
${ }^{1}$ These items were recoded from original statements: "Unimaginative," "Unoriginal," and "Uninventive." $^{2}$ Combination of "Strongly disagree," "Disagree," and "Somewhat disagree" \\
" "Neither agree nor disagree" \\
${ }^{4}$ Combination of "Strongly agree," "Agree," and "Somewhat agree"
\end{tabular}

Table 6 shows the mean values and the percent of respondents at different levels of agreement for system anxiety items. It is worth noting that the mean values do not vary much across the eight items, ranging from 2.85 to 3.59. These results indicate that the respondents do not appear to be very anxious of SAP ERP system, after practicing with the system for one semester. Eleven to thirty percent of the respondents expressed some levels of anxiety with SAP ERP system. In general, more than $60 \%$ of them were quite comfortable with the system. The respondents were more divided on "having a sinking feeling when trying to use SAP," as 30\% of the respondents agreed with this statement whereas $49 \%$ disagreed. The respondents appear to feel most comfortable with using SAP system, especially to process new transactions.

Table 6 Results of system anxiety

\begin{tabular}{|c|c|c|c|c|c|}
\hline \multirow[t]{2}{*}{ System anxiety } & \multirow[b]{2}{*}{ Mean } & \multirow[b]{2}{*}{ St. Dev. } & \multicolumn{3}{|c|}{$\%$ of students } \\
\hline & & & Disagree $^{2}$ & Neutral $^{3}$ & Agree $^{4}$ \\
\hline SAP scares $\mathrm{me}^{1}$ & 2.94 & 1.443 & 67.1 & 17.9 & 15.0 \\
\hline
\end{tabular}




\begin{tabular}{|c|c|c|c|c|c|}
\hline I have little self-confidence when it comes to working with $\mathrm{SAP}^{1}$ & 3.39 & 1.516 & 60.7 & 15.7 & 23.6 \\
\hline I have a sinking feeling when trying to use SAP & 3.59 & 1.522 & 48.6 & 21.4 & 30.0 \\
\hline I would feel uncomfortable working with $\mathrm{SAP}^{1}$ & 2.96 & 1.274 & 70.7 & 17.1 & 12.1 \\
\hline I do not feel okay about trying to process a new transaction in $\mathrm{SAP}^{1}$ & 2.85 & 1.280 & 78.6 & 10.7 & 10.7 \\
\hline I am not the type to do well with SAP & 3.11 & 1.532 & 60.7 & 21.4 & 17.9 \\
\hline I feel threatened when other talk about $\mathrm{SAP}^{1}$ & 2.95 & 1.426 & 65.0 & 17.1 & 17.9 \\
\hline
\end{tabular}

${ }^{1}$ These items were recoded from original statements.

${ }^{2}$ Combination of "Strongly disagree," "Disagree," and "Somewhat disagree"

3 "Neither agree nor disagree"

${ }^{4}$ Combination of "Strongly agree," "Agree," and "Somewhat agree"

\section{Factor analysis on system playfulness and system anxiety}

Table 7 shows the results of the factor analysis performed on the system playfulness and anxiety items. The principal axis factoring method was used in extracting the factors and varimax method was used for rotation. The results show that the two-factor solution, i.e., factor 1 of anxiety and factor 2 of playfulness, is appropriate and the items display desirable convergent and discriminant validity. Two-factor model explained $47 \%$ of the total variances. Three items of playfulness ("imaginative," "original" and "inventive") appeared to be loaded on multiple factors and were loaded in their construct lower than the recommended 0.4 (Hair et al. 1992). We decided to exclude them in creating the scale. Also, one item of anxiety ("feel threatened") loaded in its construct lower than the recommended 0.4 , and so, it was excluded in its scale. Overall, the psychometric properties of the resulting items of the two scales seem appropriate. Cronbach's alpha, which is a measure of internal consistency, was quite high at 0.883 for 4 -item playfulness and 0.881 for 7-item anxiety (Nunnally 1978). Elimination of these items also helped the scales to be more reliable.

Table 7 Factor analysis of system playfulness and system anxiety

\begin{tabular}{lrr}
\hline Scale item & Factor 1 & Factor 2 \\
\hline System Anxiety & & \\
SAP scares me* & 0.666 & -0.249 \\
Have little self-confidence with SAP* & 0.686 & -0.320 \\
Sinking feeling when trying to use SAP* & 0.674 & 0.012 \\
Uncomfortable working with SAP* & 0.726 & -0.244 \\
Not feeling OK about trying new problem* & 0.630 & -0.343 \\
Not good with SAP* & 0.815 & 0.006 \\
Not the type to do well with SAP* & 0.737 & 0.084 \\
Feel threatened when others talk about SAP & 0.372 & -0.018 \\
System Playfulness & & \\
Spontaneous* & 0.094 & 0.755 \\
Imaginative & -0.244 & 0.261 \\
Flexible* & -0.084 & 0.724 \\
Creative* & -0.165 & 0.858 \\
Playful* & -0.115 & 0.875 \\
Original & -0.218 & 0.257 \\
Inventive & -0.291 & 0.216 \\
\hline
\end{tabular}

* Items retained after factor analysis

\section{Factor analysis on learning and skills}

Table 8 shows the results of the factor analysis performed on the knowledge and skills items. The principal axis factoring method was used in extracting the factors and varimax method was used for rotation. Factor analysis extracted two distinctive factors with convergent and discriminant validity. All items loaded highly on their constructs (greater than 0.4). Both learning and skill scales were highly reliable with Cronbach's alpha at 0.962 for the 5 -item learning and 0.972 for the 7 -item skill (Nunnally 1978).

Table 8 Factor analysis of learning and skills

\begin{tabular}{lcc}
\hline Scale item & Factor 1 & Factor 2 \\
\hline Knowledge & & \\
Procurement process and activities & 0.372 & 0.862 \\
Production process and activities & 0.389 & 0.828 \\
Fulfillment process and activities & 0.407 & 0.876 \\
Warehouse management process and activities & 0.430 & 0.777 \\
$\quad$ Interrelations and interdependencies between business processes & 0.490 & 0.722 \\
Skills & &
\end{tabular}




\begin{tabular}{lll}
\hline Transactions for the procurement process & 0.792 & 0.491 \\
Transactions for the production process & 0.820 & 0.363 \\
Transactions for the fulfillment process & 0.822 & 0.427 \\
Transactions for the warehouse management process & 0.838 & 0.355 \\
Material master data & 0.776 & 0.426 \\
Customer master data & 0.803 & 0.427 \\
Vendor master data & 0.836 & 0.407 \\
\hline
\end{tabular}

Effects of playfulness and anxiety on learning and skills

Multivariate regression analysis was used to examine the effects of system playfulness and system anxiety on learning and skill development. Due to high correlations between learning and skills $(\mathrm{r}=.789)$, we believe multivariate approach is more appropriate allowing dependent variables to be correlated (Pedhazur 1982). Table 9 shows the results of regression analysis. Model 1 included playfulness or anxiety alone. Model 2 included three dummy coded variables to control for student background characteristics: one for gender and two for prior experience with SAP/ERP systems and these variables were included in all subsequent models. Male and students with no experience in both SAP system and other ERP systems served as a reference group. Model 3 included only system playfulness as a predictor with controls for gender and prior experience. Model 4 included only system anxiety as a predictor with controls for gender and prior experience, and Model 5 included both system playfulness and system anxiety as predictors with controlling for gender and prior experience.

Table 9 Summary of regression analyses

\begin{tabular}{|c|c|c|c|c|c|c|c|c|c|c|}
\hline \multirow[t]{2}{*}{ Variables } & \multicolumn{5}{|c|}{ Learning } & \multicolumn{5}{|c|}{ Skills } \\
\hline & B & SE B & $\mathrm{t}$ & $\mathrm{p}$ & $\eta^{2}$ & B & SE B & $\mathrm{t}$ & $\mathrm{p}$ & $\eta^{2}$ \\
\hline \multicolumn{11}{|l|}{ Model 1a } \\
\hline Playfulness & 0.152 & 0.072 & 2.123 & 0.036 & 0.032 & 0.146 & 0.070 & 2.083 & 0.039 & 0.031 \\
\hline \multicolumn{11}{|l|}{ Model 1b } \\
\hline Anxiety & -0.639 & 0.081 & -7.935 & 0.000 & 0.318 & -0.658 & 0.077 & -8.538 & 0.000 & 0.351 \\
\hline \multicolumn{11}{|l|}{ Model 2} \\
\hline Female & -0.060 & 0.239 & -0.251 & 0.802 & 0.001 & 0.044 & 0.235 & 0.188 & 0.851 & 0.000 \\
\hline SomeExp & 0.190 & 0.251 & 0.756 & 0.451 & 0.005 & 0.111 & 0.246 & 0.452 & 0.652 & 0.002 \\
\hline BothExp & 0.840 & 0.408 & 2.062 & 0.041 & 0.033 & 0.670 & 0.400 & 1.675 & 0.097 & 0.022 \\
\hline \multicolumn{11}{|l|}{ Model 3} \\
\hline Female & -0.055 & 0.237 & -0.233 & 0.816 & 0.000 & 0.049 & 0.233 & 0.208 & 0.835 & 0.000 \\
\hline SomeExp & 0.216 & 0.249 & 0.867 & 0.388 & 0.006 & 0.135 & 0.076 & 1.789 & 0.076 & 0.026 \\
\hline BothExp & 0.837 & 0.404 & 2.073 & 0.040 & 0.034 & 0.667 & 0.397 & 1.679 & 0.096 & 0.023 \\
\hline Playfulness & 0.135 & 0.076 & 1.789 & 0.076 & 0.026 & 0.121 & 0.074 & 1.632 & 0.105 & 0.021 \\
\hline \multicolumn{11}{|l|}{ Model 4} \\
\hline Female & 0.048 & 0.202 & 0.239 & 0.812 & 0.000 & 0.157 & 0.193 & 0.810 & 0.420 & 0.005 \\
\hline SomeExp & 0.167 & 0.211 & 0.790 & 0.431 & 0.005 & 0.088 & 0.202 & 0.434 & 0.665 & 0.002 \\
\hline BothExp & 0.453 & 0.348 & 1.301 & 0.196 & 0.014 & 0.267 & 0.333 & 0.804 & 0.423 & 0.005 \\
\hline Anxiety & -0.611 & 0.085 & -7.146 & 0.000 & 0.295 & -0.634 & 0.082 & -7.752 & 0.000 & 0.330 \\
\hline \multicolumn{11}{|l|}{ Model 5} \\
\hline Female & 0.048 & 0.203 & 0.235 & 0.814 & 0.000 & 0.156 & 0.194 & 0.806 & 0.422 & 0.005 \\
\hline SomeExp & 0.173 & 0.213 & 0.813 & 0.418 & 0.005 & 0.090 & 0.203 & 0.440 & 0.661 & 0.002 \\
\hline BothExp & 0.458 & 0.349 & 1.310 & 0.193 & 0.014 & 0.269 & 0.334 & 0.804 & 0.423 & 0.005 \\
\hline Playfulness & 0.028 & 0.066 & 0.416 & 0.678 & 0.001 & 0.009 & 0.064 & 0.134 & 0.893 & 0.000 \\
\hline Anxiety & -0.602 & 0.088 & -6.819 & 0.000 & 0.278 & -0.631 & 0.085 & -7.467 & 0.000 & 0.315 \\
\hline
\end{tabular}

Model 1a shows significant positive effect of playfulness on learning and skills $(t=2.123, \mathrm{p}<.05$ for learning, $\mathrm{t}=2.083, \mathrm{p}<.05$ for skills) whereas Model $1 \mathrm{~b}$ show significant negative effect of anxiety ( $\mathrm{t}=-7.935, \mathrm{p}<.001$ for learning, $\mathrm{t}=-8.538, \mathrm{p}<.001$ for skills) when each one was entered alone in the model. As for the effect of student background characteristics, there were no significant differences between male and female students across all models for both learning and skill development. However, prior experience was a significant predictor for learning but not for skill development in Models $2 \& 3$. Results of Models $2 \& 3$ show significant effect of prior experience of both SAP system and other ERP systems for learning ( $\mathrm{t}=2.062, \mathrm{p}<.05$ for Model 2, $\mathrm{t}=2.073, \mathrm{p}<.05$ for Model 3 ) whereas it was not a significant predictor for skills. In other words, students who had prior experience with both SAP system and other ERP systems had significantly higher means in learning compared to students who did not have any experience before. Effect size expressed as partial eta squared shows prior experience in both SAP system and other ERP systems had a small effect on learning $\left(\eta^{2}=.03\right)^{1}$.

\footnotetext{
${ }^{1} .02$ for small effect size, .15 for medium effect size and .35 for large effect size (Cohen 1988).
} 
Playfulness was a significant predictor in Model 1 but lost its significance when playfulness was entered in the model with controls for background characteristics for both learning and skills. Table 2 shows significant and positive relationship between playfulness and knowledge and between playfulness and skill $(r=.180, p<.05)$. On the other hand, system anxiety had significant negative effects on both learning and skills when it was entered as the only predictor in Model 4 ( $\mathrm{t}=-7.146, \mathrm{p}<.001$ for learning; $\mathrm{t}=-7.752, \mathrm{p}<.001$ for skills). Partial eta squared were .295 for learning and .330 for skills indicating the large effect size of anxiety. When both system playfulness and anxiety were entered in Model 5, negative effects of system anxiety on learning and skills stay significant ( $\mathrm{t}=-6.819, \mathrm{p}<.001$ for learning; $\mathrm{t}=-7.467, \mathrm{p}<.001$ for skills) with medium to large effect size. It appears that having favorite perceptions about the system does not help students much to improve their knowledge and skills but having high level of system anxiety has much bigger negative impact on their learning and skills.

Figure 3 summarizes the results of hypothesis testing. H1 hypothesized that system playfulness has a positive effect on learning of business processes whereas $\mathrm{H} 2$ hypothesized that system playfulness has a positive effect on skills to use the system. Both $\mathrm{H} 1$ and $\mathrm{H} 2$ were not supported. The effects of system playfulness on learning and skills were not significant after student gender and prior experience were controlled for. H3 hypothesized that system anxiety has a negative effect on learning of business processes whereas $\mathrm{H} 4$ hypothesized that system anxiety has a negative effect on student skills to use the system. Both $\mathrm{H} 3$ and $\mathrm{H} 4$ were supported with medium to large effect size. The effects of system anxiety on learning and skills were found to be negative and significant with or without system playfulness in the model. $\mathrm{R}^{2}$ change statistics (in brackets) show system anxiety alone explained additional $29 \%$ of the variances in learning and $32 \%$ of variances in skill. On the contrary, playfulness alone explained only $3 \%$ of variances in learning and $1 \%$ of the variances in skill.

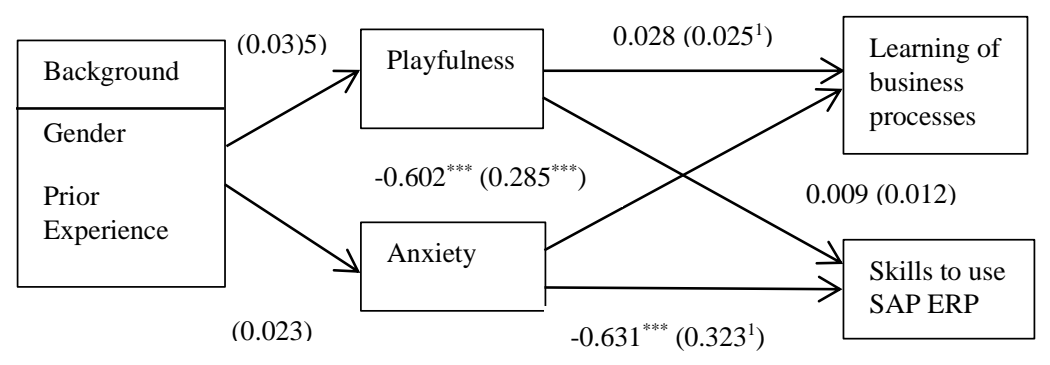

${ }^{1} R^{2}$ change in bracket after backgrounds were controlled

$* \mathrm{p}<0.05, * * \mathrm{p}<0.01, * * * \mathrm{p}<0.001$

Fig. 3 Results of hypothesis testing

\section{Summary and Discussion}

This study attempted to examine the users' perceptions toward SAP ERP system regarding system playfulness and system anxiety, and the effects of system playfulness and system anxiety on users' learning of business processes and skills to use the system. Our results indicate that users maintain neutral perceptions about SAP ERP system as being neither playful nor unplayful even after they have gained some experiences with the system. On the contrary, our results indicate that users feel less anxiety with the system after they have gained experiences with the system over the semester.

System anxiety is found to have a significant and negative effect on learning of business processes and skills to use the system. When students have higher level of anxiety in using the system, they perceive the levels of their knowledge and skills to be low. On the contrary, system playfulness is found not to have significant effects on learning and skills once the student background characteristics were accounted for. System anxiety plays a far more important role in their perceptions of their knowledge and skills. These results suggest that enhancing the playfulness of SAP ERP system may help improve the user's learning of business processes and skills to use the system, but that reducing the anxiety of the system is much more important in improving both the user's learning of business processes as well as the user's skills to use the system. Taken together, the findings of this study can help explicate the user perceptions towards SAP ERP system, and such understanding will prove a helpful viewpoint on user adoption of SAP ERP system. Practices and real-world experience will help students feel more comfortable in using the system. Considering the large effects of system anxiety on learning and skills, it warrants more efforts need to be made to reduce students' anxiety by providing structural practices and real-world applications. 
A few limitations are recognized in this study. First, we considered only two perceptual factors regarding SAP ERP system. These factors are certainly not comprehensive. We need to develop instruments that are more comprehensive and are capable, with a high degree of validity and reliability, of capturing and operationalizing the factors associated with user experiences with SAP ERP system. Second, we examined only the perceptions of students toward SAP ERP system in a classroom setting. It would be important to examine the perceptions of actual users of the system in the real business world longitudinally. In fact, the participants played the distribution game of ERPsim in the last week of the semester before they completed the survey questionnaire. ERPsim is a business simulation game for SAP ERP system in which participants use the system to manage their virtual company in a competitive market (ERPsim, 2019). As ERPsim is not very different from SAP ERP system used in the real world, the perceptions of the participants in this study may not be so different from those of SAP ERP system users in the real world. Third, we may consider encompassing other ERP systems used by many people for more balanced and generalizable findings. Third, the results of this study are somewhat weak because of the small sample size and inherent problems related to perceptual studies. These limitations are certainly not exhaustive, but important ones.

\section{Acknowledgements}

Support for travel expenses pertaining to this study was provided by the Institute for International Business of the Stillman School of Business at Seton Hall University for Sung J. Shim. We highly appreciate the reviewers' insightful and helpful comments on our earlier manuscript.

\section{References}

Cohen, J. (1988). Statistical power analysis for the behavioral sciences. Hillsdale, NJ: Lawrence Erlbaum Associates, Inc.

Compeau, D. R. \& Higgins, C. A. (1995). Computer self-efficacy: Development of a measure and initial test. Management Information Systems Quarterly, 9(2), pp. 89-211.

Elkhani, N., Soltani, S. \& Ahmad, M. N. (2014). The effects of transformational leadership and ERP system selfefficacy on ERP system usage. Journal of Enterprise Information Management, 27(6), pp. 759-785.

ERPsim (2019). ERPsim, the business simulation for SAP. Retrieved from https://erpsim.hec.ca/en/erpsim, Accessed on March 2, 2019.

Ganzel, R. (1998). Feeling squeezed by technology? Training, 35(4), pp. 62-70.

Gattiker, T. F., \& Goodhue, D. L. (2005). What happens after ERP implementation: Understanding the impact of interdependence on plant-level outcomes. MIS Quarterly, 29(3), pp. 559-585.

Hung, S. Y. \& Liang, T. P. (2001). Effect of computer self-efficacy on the use of executive support systems. Industrial Management \& Data Systems, 101(5), pp. 227-237.

Saadé, R. G. \& Kira, D. (2009). Computer anxiety in e-learning: The effect of computer self-efficacy. Journal of Information Technology Education, Volume 8, pp. 177-191.

Hackbarth, G., Grover, V., \& Yi, M. Y. (2003). Computer playfulness and anxiety: Positive and negative mediators of the system experience effect on perceived ease of use. Information \& Management, Volume 40, pp. 221 232.

Hair, J. F., Anderson, R. E., Tatham, R. L., \& Black, W. C. (1992). Multivariate data analysis with readings. Upper Saddle River, NJ: Prentice-Hall.

Herzig, P., Strahringer, S., \& Ameling, M. (2012). Gamification of ERP systems - Exploring gamification effects on user acceptance constructs. Proceedings of the MKWI 2012, pp. 793-804.

Hsu, C., Chang, K., \& Chen, M. (2012). The impact of website quality on customer satisfaction and purchase intention: perceived playfulness and perceived flow as mediators. Information Systems and E-Business Management, 10(4), pp. 549-570.

Jashapara, A. \& Tai, W. (2011). Knowledge mobilization through e-learning systems: Understanding the mediating roles of self-efficacy and anxiety on perceptions of ease of use. Information Systems Management, 28:1, pp. 71-83.

Jo, J., Park, J., Ji, H., Yang, Y., \& Lim, H. (2016). A study on factor analysis to support knowledge based decisions for a smart class. Information Technology and Management, 17(1), pp. 43-56.

Laosethakul, K. \& Leingpibul, T. (2010). Why females do not choose computing? A lesson learned from China. Multicultural Education \& Technology Journal, 4(3), pp. 173-187. 
Lauchlan, S. (2017). How SAP became the world's third largest independent software supplier. Retrieved from http://www.computerweekly.com/feature/How-SAP-became-the-worlds-third-largest-independentsoftware-supplier, accessed on October 10, 2018.

Magal, S. M. \& Word, J. (2017). Business Process Integration with SAP ERP. Epistemy Press LLC.

Nunnally, J. C. (1978). Psychometric Theory (2nd ed.). New York: McGraw-Hill.

Marakas, G. M., Yi, M. Y, \& Johnson, R. D. (1998). The multilevel and multifaceted character of computer selfefficacy: Toward clarification of the construct and an integrative framework for research information. Information Systems Research, 9(2), pp. 126- 163.

Mouakket, S. (2010). Extending the technology acceptance model to investigate the utilization of ERP systems. International Journal of Enterprise Information Systems, 6(4), 38-54.

Park, J. H., Suh, H. J. \& Yang, H.D. (2007). Perceived absorptive capacity of individual users in performance of enterprise resource planning (ERP) usage: the case for Korean firms. Information and Management, 44(3), pp. 300-312.

Pedhazur, E. J. (1982). Multiple Regression in Behavioral Research (2nd ed.). Fort Worth, TX: Holt, Rinehart and Winston.

SAP University Alliances (2018). SAP University Alliances: Building Talent for the Digital Future. Retrieved from http://www.sap.com/training-certification/university-alliances.html, accessed on October 10, 2018.

Simonson, M. R., Maurer, M., Montag-Torardi, M., \& Whitaker, M. (1987). Development of a standardized test of computer literacy and a computer anxiety index. Journal of Educational Computing Research, 3(2), pp. 231247.

Terzis, V., Moridis, C. N., \& Economides, A. A. (2018). Continuance acceptance of computer based assessment through the integration of user's expectations and perceptions. Computers \& Education, Volume 62, pp. 5061.

Venkatesh, Y. \& Davis, F. D. (2000). A theoretical extension of the technology acceptance model: Four longitudinal field studies. Management Science, 46(2), pp. 186-204.

Webster, J. (1989). Playfulness and Computers at Work. Unpublished Doctoral Dissertation, New York University.

Webster, J. \& Martocchio, J. J. (1992). Microcomputer playfulness: Development of a measure with workplace implications. MIS Quarterly, 16(2), pp. 201-226.

Wildstrom, S. H. (1998). They're mad as hell out there. Business Week, 3600, pp. 32-33. 